\title{
Los mecanismos de reparación integral (RIT) como elementos unificadores del ordenamiento internacional y el derecho nacional en busca de la consolidación del Ius Commune Interamericano
}

\author{
Comprehensive repair mechanisms (RIT) as unifying elements \\ of the international law and national law in search of the \\ consolidation of the inter-ius commune
}

\begin{abstract}
Alfonso Jaime Martínez Lazcano
Abogado por la Universidad Nacional Autónoma de México; máster en Derecho Constitucional y Amparo por la Facultad de Derecho de la Universidad Autónoma de Chiapas; doctor en Derecho Público por la Universidad del Sur, México; profesor honorario de la Facultad de Derecho de la Universidad Nacional Autónoma de México (UNAM); profesor de la Universidad de Chiapas. Correoelectrónico:lazcanoalf14@hotmail.com

Jaime Alfonso Cubides Cárdenas

Abogado, especialista en Derecho Público por la Universidad Autónoma de Colombia; especialista y magíster en Docencia e Investigación con énfasis en Ciencias Jurídicas y maestría (en curso) en Derecho Administrativo por la Universidad Sergio Arboleda (Col.); doctorado (en curso) en Derecho Universidad de Buenos Aires. Docente investigador Universidad Católica de Colombia. Correo electrónico: jacubides@ucatolica.edu.co
\end{abstract}

Wisman Johan Díaz Castillo

Investigador auxiliar - Línea de investigación Derecho Agrario, grupo de investigación Derecho Verde de la Fundación Universitaria Agraria de Colombia, Uniagraria. Correo electrónico: wisman_diaz@hotmail.com

\begin{abstract}
Resumen
Las principales obligaciones que tienen los Estados con sus habitantes e incluso con la comunidad internacional es promover, respetar, proteger y garantizar los derechos humanos, deber que se refuerza después de las atrocidades cometidas en la Segunda Guerra Mundial, pero en la realidad latinoamericana están lejos de cumplirse, pues han existido dictaduras, corrupción, inmunidad, desigualdad social y abusos de autoridad graves, periodos incontrolables, desatando violencia a niveles de crueldad, indudablemente han amedrentado los derechos de las personas, ante estas situaciones los Estados tienen el deber de reparar de forma integral a las víctimas por las conductas u omisiones injustas, con los parámetros internacionales convencionales; de esta manera, la presente investigación busca determinar si México y Colombia han reparado efectivamente a las víctimas de cada uno de los conflictos acontecidos en esas naciones, además de determinar si esas medidas cumplen con los lineamientos suscritos regional e internacionalmente, con el fin de establecer la posibilidad de que la reparación integral sea una de la formas en las que se consolida el ius commune interamericano, por lo que se desarrollará este escrito en cuatro ejes temáticos: i) Conceptualización de la víctima y sus respectivos derechos, ii) Establecer la reparación integral en el marco interamericano, iii) Medidas de reparación integral a nivel nacional, iv) Avances en la consolidación del ius commune interamericano.
\end{abstract}

Palabras clave: Víctimas, reparación integral, obligaciones internacionales. 


\begin{abstract}
The main obligation of a State with its inhabitants and even the international community is to protect the fundamental rights of each of them, an obligation that is reinforced after the atrocities of World War II, but in the Latin American reality this lay this obligation to be fulfilled by these countries, because in each of these territories have been dictatorships and abuses of authority that have unleashed uncontrollable periods of strong violence, which have undoubtedly intimidated rights of individuals in these situations States to not fulfill their respective loads, they are on duty to compensate each of the victims affected by such conduct, complying with international standards uttered on the rights of the victims; thus the present investigation seeks to determine whether they have been repaired effectively to victims of each of the conflicts that occurred in those nations in the countries of Mexico and Colombia, in addition to determining whether these measures comply with the guidelines regionally and internationally They ask, in order to establish the possibility that full reparation is one of the ways in which the ius commune Inter, for which this paper was developed in four thematic areas is consolidated: i) conceptualization of the victim and their respective rights, also establishing ii) Full compensation in the inter-frame and their respective iii) measures of reparation at national level to end the iv) Progress in strengthening the inter-American ius commune
\end{abstract}

Keywords: Victims, reparation, international obligations.

\title{
Résumé
}

Les principales obligations des Etats avec leurs habitants et même la communauté internationale est de promouvoir, respecter, protéger et garantir les droits de l'homme, des droits renforcés après les atrocités de la Seconde Guerre mondiale, mais dans la réalité latino-américaine sont loin remplies, parce qu'il ya eu des dictatures, la corruption, l'immunité, l'inégalité sociale et l'abus de pouvoir, de graves périodes incontrôlables, déchaînant la violence à des niveaux de cruauté sans aucun doute ont intimidés les droits des personnes dans ces situations États ont le devoir de réparation des de manière holistique les victimes de comportements ou d'omissions injustes, avec les normes internationales conventionnelles; ainsi, cette enquête vise à déterminer si le Mexique et la Colombie ont été réparés efficacement aux victimes de chacun des conflits survenus dans ces pays, et de déterminer si ces mesures sont conformes aux directives régionales signées et international, afin de établir la possibilité que la réparation intégrale est l'une des façons dont la commune de ius inter consolidés, de sorte que cet article sera mis au point dans quatre domaines thématiques: i) Conceptualisation de la victime et de leurs droits respectifs, ii) établir la réparation intégrale dans le cadre interaméricain, iii) les mesures de réparation intégrale au niveau national, iv) les progrès réalisés dans le renforcement de la ius commune inter-américaine.

Mots-clés: les victimes réparation, obligations internationales. 


\title{
Los mecanismos de reparación integral (RIT) como elementos unificadores del ordenamiento internacional y el derecho nacional en busca de la consolidación del Ius Commune Interamericano*
}

\author{
Alfonso Jaime Martínez Lazcano \\ Jaime Alfonso Cubides Cárdenas \\ Wisman Johan Díaz Castillo
}

\section{INTRODUCCIÓN}

El hombre desde una concepción aristotélica es sociable por naturaleza, hecho que se ratifica al vivir en sociedad o comunidad desde sus orígenes, colectividades que poco a poco evolucionaron en las formas complejas actuales, donde uno de los principales elementos unificadores es el Estado, como autoridad legitimada popularmente para gobernarlos, dado que cada uno de los miembros de la sociedad dieron tal facultad al Estado con la esperanza de que este los protegiera de cualquier tipo de vulneración tal y como lo describe la escuela del contrato social, está en la obligación de tutelar por su bienestar ese Estado implicando para ello la utilización de fuertes políticas públicas que la materialicen, pero la realidad dista de la ficción, más aun en el contexto latinoamericano donde las dictaduras en el siglo pasado produjeron consecuencias graves, que aun en este siglo son notorias, pero estas violaciones no

* $\quad$ Este artículo contiene resultados del proyecto de investigación: “Avatares jurídicos de la Restitución de Tierras" que hace parte de la línea de investigación Derecho Agrario del grupo de investigación: Derecho Verde, registrado con el código COL0043709 en Colciencias, adscrito y financiado por la Facultad de Ciencias Jurídicas y Sociales de la Fundación Universitaria Agraria de Colombia, Uniagraria. 
solo fueron fruto de dictaduras, sino que también se consumían en Estados donde los abusos de la autoridad eran indiscriminados, además de la existencia de estados de sitio prolongados, siendo el escenario perfecto para que se realizar conductas que atentaron gravemente contra los derechos de las personas.

Ante estas vulneraciones y la imposibilidad de cumplir con su obligación principal de protección, los Estados se ven inmersos en deberes accesorios a este incumplimiento dentro de los cuales está la efectiva materialización de los derechos de las víctimas, como lo son la verdad, la justicia y la reparación, en referencia a este último ha sido muy amplia la jurisprudencia interamericana que habla sobre él, pues lo ha dotado de elementos teóricos que desarrollan su contenido compilando al mismo tiempo la Corte Interamericana de Derecho Humanos (Corte IDH) los postulados internacionales con producción netamente regional, este trabajo ha tenido acogida en los países latinoamericanos, como es el caso colombiano donde se han realizado avances jurisprudenciales y legislativos en esta materia, por su parte el Estado mexicano con las reformas legislativas y judiciales (Calderón, 2013, p. 207) busca no solo consagrar la reparación integral en su ordenamiento, sino que también cumplir las medidas que la misma Corte IDH le ha solicitado realizar en favor de las víctimas, igualmente, encontramos a la Ley General de Víctimas como la adaptación mexicana de carácter legislativo que elaboró aplicando los preceptos convencionales.

Con estas adopciones que realizan los Estados internamente cabría preguntarse si ¿están logrando constituir un ius commune interamericano?, realizando una sinergia entre los sistemas universales y regionales con cada uno de los ordenamientos nacionales para la efectiva protección de los derechos de las personas. Pero para poder dar una solución concreta y vehemente a este interrogante es necesario brindar los conceptos necesarios para tal fin, comenzando por la víctima y su complejo dogmático como acreedor de las reparaciones.

\section{Conflicto armado no internacional}

Uno de los elementos intrínsecos para poder establecer y determinar en qué circunstancias se adquiere la calidad de víctima -como factor preliminar en el desarrollo de la presente investigación-, es la ocurrencia de un conflicto armado del cual se desprenden la comisión de conductas generadoras de graves vulneraciones a los derechos fundamentales de las personas civiles ajenas a los interés de dicho conflicto, que tampoco tienen ninguna relación con alguno de los actores de ese enfrentamiento armado, obteniendo por consiguiente tal calidad. Por estas razones antes de abordar en concreto el concepto de víctima y sus derechos, es necesario antes de ello entender el contexto en que surgen estas víctimas, que como se mencionó es en medio de los conflictos armados, los cuales son regulados por el derecho internacional más específicamente por los cuatro convenios de Ginebra y sus dos protocolos adicionales, en los cuales se clasifican dos tipos de conflictos armados, uno de carácter no internacional y el otro de naturaleza internacional. 
Este último está desarrollado por el artículo segundo común de los cuatro convenios de Ginebra, en el cual se establece que: el presente Convenio se aplicará en caso de guerra declarada o de cualquier otro conflicto armado que surja entre dos o varias Altas Partes Contratantes, aunque una de ellas no haya reconocido el estado de guerra ${ }^{1}$, explicando este artículo el profesor Vité, advierte que las mencionadas Altas Partes son entidades soberanas, en otras palabras, los Estados, asimismo este profesor manifiesta que la característica internacional de un conflicto armado también se otorga en aquellos eventos donde otro Estado ayuda a una fuerza no gubernamental que combate internamente a otro Estado, además manifiesta que otra de las situaciones donde se determina un conflicto armado internacional ocurre cuando existe un grupo de liberación que esté luchando contra un Estado que haya ocupado ese territorio.

Por otra parte en materia de conflicto armado no internacional encontramos su descripción en el artículo tercero común de los cuatro Convenios de Ginebra de 1949, donde se contempla que este tipo de conflicto se presenta entre fuerzas no gubernamentales y las fuerzas estatales, pues el derecho internacional humanitario como ordenamiento aplicado a este tipo de conflictos, demanda tanto del Estado como de los grupos armados ilegales, partícipes de este enfrentamiento interno las correspondientes obligaciones humanitarias en el mismo, tal y como lo expresa la doctrina (Betancur, 2010 p. 74), ahora bien en el marco de la presente investigación y teniendo en cuenta que los mayores conflictos del siglo pasado y el presente en esta región son conflictos internos ${ }^{2}$, se entenderá a las víctimas dentro del contexto de los conflictos no internacionales o interno.

1 Artículo completo: Aparte de las disposiciones que deben entrar en vigor ya en tiempo de paz, el presente Convenio se aplicará en caso de guerra declarada o de cualquier otro conflicto armado que surja entre dos o varias Altas Partes contratantes, aunque una de ellas no haya reconocido el estado de guerra. El Convenio se aplicará también en todos los casos de ocupación total o parcial del territorio de una Alta Parte contratante, aunque tal ocupación no encuentre resistencia militar. Si una de las potencias en conflicto no es parte en el presente Convenio, las potencias que son partes en este estarán, sin embargo, obligadas por él en sus relaciones recíprocas. Estarán, además, obligadas por el Convenio con respecto a dicha Potencia, si esta acepta y aplica sus disposiciones (artículo segundo Común a los cuatro Convenios de Ginebra de 1949).

2 Esto se pude ratificar con las siguientes cifras: La violencia no es únicamente obra de criminales, es también policial: en 2007, la policía mató a más de 1300 jóvenes en Río de Janeiro y a cerca de 500 en São Paulo. La comparación de estas cifras con el número de muertos por la policía en Estados Unidos, cerca de 200 personas (Folha de São Paulo, 23, 12, 2007), ayuda a valorar la importancia de la violencia policial. Esta no es exclusiva de Brasil; existe en numerosos países latinoamericanos. Sin embargo, la intensidad de la violencia difiere notablemente en los países latinoamericanos. Es muy elevada en Colombia, donde llega a 84,6 homicidios por cada 100000 habitantes; y llega a 43 en El Salvador, a 33 en Venezuela, a 31 en Brasil, a 12 en México, y a 7 en Argentina y Costa Rica, un poco menor que en Estados Unidos, pero más alta que en Canadá (2). En cada uno de estos países, la violencia está distribuida desigualmente en el espacio. Tiende a concentrarse en algunas ciudades grandes (Recife, Río de Janeiro y São Paulo en Brasil; Cali, Medellín y Bogotá en Colombia), pero desde hace poco se extiende a las ciudades medianas (Salama, 2008, p. 82). 


\section{Derechos de las víctimas}

Gracias al análisis que se realizó sobre la tipología de los conflictos armados se esclareció el contexto en el que las personas obtienen la calidad de "víctimas", sin embargo, con el fin de analizar cada uno de los derechos inherentes a esta población es menester conceptualizar esta definición, labor que ha sido adelantada en la Ley de Víctimas y Restitución de Tierras (Ley 1448 del 2011) de Colombia, la cual nos da una primera noción, pues para el legislador víctimas son: "aquellas personas que individual o colectivamente hayan sufrido un daño por hechos ocurridos a partir del 1 de enero de 1985, como consecuencia de infracciones al Derecho Internacional Humanitario $^{3}$ o de violaciones graves y manifiestas a las normas internacionales de Derechos Humanos, ocurridas con ocasión del conflicto armado interno en este país"; en el caso mexicano la ley General de Víctimas amplia el contenido dado por el Congreso Colombiano dado que no solo conceptualiza la calidad de víctima, sino que también enumera varios tipos dentro de los cuales encontramos: las víctimas i) directas, ii) indirectas, y iii) potenciales ${ }^{4}$ Adicionalmente a esta conceptualización legislativa, el DIH presenta a la víctima como toda persona que en medio de un conflicto armado no participa en ninguno de los bandos combatientes, convirtiéndose de ese modo en una persona civil a la cual no se le pueden vulnerar sus derechos durante dicho conflicto, tomando estas definiciones y las características que las Naciones Unidas ha dado en esta materia ${ }^{5}$ podemos concluir que víctima es aquella

3 La distinción entre civiles y combatientes, más que un principio fundamental es un axioma del DIH, en virtud del cual todas las partes beligerantes en un conflicto armado deben hacer una distinción clara entre esas dos categorías de personas, distinción que lleva implícita a su vez la obligación, para los combatientes, de distinguirse de los civiles que no pueden ser atacados ni involucrados en las hostilidades (Lozano, 2006, p. 105).

4 Se denominarán víctimas directas aquellas personas físicas que hayan sufrido algún daño o menoscabo económico, físico, mental, emocional, o en general cualquiera puesta en peligro o lesión a sus bienes jurídicos o derechos como consecuencia de la comisión de un delito o violaciones a sus derechos humanos reconocidos en la Constitución y en los Tratados Internacionales de los que el Estado mexicano sea parte. Son víctimas indirectas los familiares o aquellas personas físicas a cargo de la víctima directa que tengan una relación inmediata con ella. Son víctimas potenciales las personas físicas cuya integridad física o derechos peligren por prestar asistencia a la víctima, ya sea por impedir o detener la violación de derechos o la comisión de un delito. La calidad de víctimas se adquiere con la acreditación del daño o menoscabo de los derechos en los términos establecidos en la presente Ley, con independencia de que se identifique, aprehenda, o condene al responsable del daño o de que la víctima participe en algún procedimiento judicial o administrativo. Son víctimas los grupos, comunidades u organizaciones sociales que hubieran sido afectadas en sus derechos, intereses o bienes jurídicos colectivos como resultado de la comisión de un delito o la violación de derechos (artículo 4 de la Ley General de Víctimas).

5 Resolución 40/34 de 1985 de las Naciones Unidas: a. Personas que, individual o colectivamente, han sufrido un perjuicio, especialmente un ataque a su integridad psíquica o mental, un sufrimiento moral, una pérdida material, o un ataque grave a sus derechos fundamentales, en razón de acciones y omisiones que infringen las leyes penales en vigor en un Estado miembro, abarcando aquellas que prohíben los abusos criminales de poder. b. Una persona puede ser considerada como una "víctima", en el ámbito de la presente Declaración, tanto si el autor ha sido o no identificado, detenido, perseguido o declarado culpable, y cualesquiera que sean sus lazos de parentesco con la víctima. El término "víctima" incluye también llegado el caso, la familia próxima o las personas a 
persona a la cual se le han transgredido sus derechos de manera sicología mental y física, que esta categoría pude ser otorgada de manera individual o colectiva y por último los familiares cercanos de la persona que sufrió prima fase dichas violaciones también son llamados a ser acreedores, a ser llamados víctimas ${ }^{6}$.

Cuando se configuran las situaciones anteriores estas personas que adquieren el estatus de víctima tienen los siguientes derechos: la justicia y la verdad como complementarias y como elementos de un paquete de medidas que comprenden además de la justicia y la verdad, la reparación y las garantías de no repetición (Cortés, 2007, p. 66) ) $^{7-8}$; parámetros ratificados por la resolución 2005/35 de las Naciones Unidas que establece tres derechos para ellos: i) Acceso igual y efectivo a la justicia; ii) Reparación adecuada, efectiva y rápida del daño sufrido; y iii) Acceso a información pertinente sobre las violaciones y los mecanismos de reparación (Leadtith, 2009, p. 4) ${ }^{9}$; en igual sentido se ha dicho que: en la actualidad, los procesos de justicia transicional en el mundo responden a la fórmula de conseguir "verdad, justicia y reparación"10 para las víctimas de actos atroces y violatorios de los derechos

cargo de la víctima directa y las personas que han sufrido un perjuicio al intervenir en ayuda de las víctimas necesitadas o por evitar la victimización. c. Las disposiciones de la presente sección se aplican a todos, sin distinción alguna de raza, de color, de sexo, de edad, de lengua de religión, de nacionalidad, de opinión política o cualquier otra, de creencias o prácticas culturales, de fortuna, de nacimiento o de situación familiar, de origen étnico o social, y de capacidad psíquica (Leadtith, 2009, p. 3).

6 En Colombia siguiendo los parámetros internacionales víctima son: las personas naturales o jurídicas y demás sujetos de derechos que individual o colectivamente hayan sufrido algún daño directo como consecuencia del injusto. La condición de víctima se tiene con independencia de que se identifique, aprehenda, enjuicie o condene al autor del injusto e independientemente de la existencia de una relación familiar con este (Raba, 2012, pp. 66-67).

7 Los derechos a la verdad, la justicia y la reparación son el catálogo definido por Lois Joinet y adoptado tanto en el contexto del Sistema Interamericano como europeo de derechos humanos, que ha sido plasmado y desarrollado por la jurisprudencia, en concreto la de la Corte Interamericana, y aplicado por la Corte Constitucional colombiana en sus providencias, de manera reiterada y consistente (Raba, 2012, p. 69).

8 Los principios de van boven/ bassiouni adoptados por la Asamblea General de las Naciones Unidas en el 2005: Establecen los derechos de las víctimas de violaciones manifiestas de los derechos humanos o de graves infracciones al Derecho Internacional Humanitario a acceder a medidas o un recurso efectivo y obtener reparación y las obligaciones de los Estados en prevenir violaciones, investigar, perseguir y sancionar a los perpetradores, brindar un acceso efectivo a la justicia a las víctimas y otorgar una reparación integral (Noguera, 2010, p. 102).

9 También el Principio 19 de los principios para la protección y la promoción de los derechos humanos mediante la lucha contra la impunidad elaborados en el $43^{\circ}$ periodo de sesiones: Garantías contra la utilización de la reconciliación o el perdón para fomentar la impunidad. No existe reconciliación justa y duradera sin que se satisface efectivamente la necesidad de justicia; el perdón es, sin duda, un factor importante de la reconciliación, pero supone, como acto privado, que la víctima o sus derechohabientes conozcan el autor de las violaciones y que este haya tenido la posibilidad de reconocer los hechos y manifestar su arrepentimiento.

10 En esta materia la Ley General de Víctimas estipula en el numeral 1 del artículo $2^{\circ}$ que: Reconocer y garantizar los derechos de las víctimas del delito y de violaciones a derechos humanos, en especial el derecho a la asistencia, protección, atención, verdad, justicia, reparación integral, debida diligencia y todos los demás derechos consagrados en ella, en la Constitución, en los Tratados Internacionales de derechos humanos de los que el Estado mexicano es parte y demás instrumentos de derechos humanos. 
humanos (Casas-Casas \& Herrera-Tolosa, 2008, p. 200). Con estos insumos teóricos se puede establecer que son tres los derechos principales que tienen toda víctima: derecho a la justica, a la verdad y a la reparación ${ }^{11-12}$, proseguiremos a conceptualizar a cada uno de estos.

\section{Derecho a la justica}

Parafraseando al profesor Méndez el acceso a la justica es una característica fundamental que demuestra la plena garantía que tienen los derechos humanos en los Estados, pues su protección solo se evidencia cuando son amparados en los momentos que necesitan de dicha tutela y esto ocurre después de haber sufrido algún tipo de violación (Méndez, 2000, p. 2) si posteriormente a la vulneración las víctimas pueden acceder fácilmente a procesos y mecanismo que los protejan, se estará permitiendo el goce pleno de esta garantía, sin embargo, no se puede creer que con la simple existencia de dichos mecanismo se cumple con los preceptos que demanda este derecho ya que tiene que estar acompañado por las siguientes características según lo expuso el profesor Leadith: en primer lugar el i) acceso a los proceso, recursos o mecanismos de justicia tiene que tener un carácter igualitario, a la par, ii) dichos mecanismos también se deben presentar en sede administrativa, iii) estos procesos deben ser siempre justos e imparciales, iv) asimismo, han de darse a conocer a toda la sociedad de igual manera, v) dentro de estos recursos o procesos corresponde establecerse medidas de contención y protección a la víctima y, por último, vi) facilitar el apoyo necesario a estas personas durante todo el proceso ${ }^{13}$.

11 Para mayor información ver: El proceso de construcción y consolidación de la paz comienza con la puesta en marcha de mecanismos de justicia transicional con el objetivo de garantizar el derecho de las víctimas a acceder de manera efectiva a la justicia; obtener información pertinente sobre los crímenes cometidos y los mecanismos de reparación; y recibir una reparación adecuada, efectiva y rápida del daño sufrido, que incluya en particular medidas de restitución, indemnización, rehabilitación, satisfacción y garantías de no repetición. Los principios anteriormente citados definen la satisfacción como la verificación de los hechos y la revelación pública y completa de la verdad, en la medida en que esa revelación no provoque más daños o amenace la seguridad y los intereses de la víctima, de sus familiares, de los testigos o de personas que han intervenido para ayudar a la víctima o impedir que se produzcan nuevas violaciones (Marcellan, 2010, p. 16).

12 Estos derechos se desarrollan mediante: Un informe público sobre memoria o sobre verdad, la instauración de una comisión o de un grupo de comisionados de reputado prestigio, son necesarios pero no suficientes en un proceso plural y sostenible de esclarecimiento, justicia y reconciliación. A esto se añade que las memorias y las historias políticas de la represión y del terror que producen diversos actores políticos y sociales deben constantemente reactualizarse y pluralizarse, deben estar siempre abiertas al escrutinio, al debate, a la discusión pública; es más, la memoria y la verdad deben historiarse continuamente para evitar ambigüedades y falta de coherencia y la historia debe abrirse a las memorias con el fin de pluralizarse (Jaramillo-Marín, 2010, p. 17).

13 Para mayor información ver: En relación con el acceso igual y efectivo a la justicia se señala que la víctima de una violación manifiesta de las normas internacionales de derechos humanos o de una violación grave del derecho internacional humanitario, tendrá un acceso igual a un recurso judicial efectivo, conforme a lo previsto en el derecho internacional. Al igual que el recurso que tiene la víctima para el acceso a órganos administrativos y de otra índole, así como a mecanismos, modalidades y procedimientos utilizados conforme al derecho interno. 
Con la aplicación de cada una de estas características se puede hablar que el acceso a la justicia como derecho que tiene toda víctima, es efectivo, con lo cual se estaría satisfaciendo plenamente este derecho a las personas que sufrieron algún tipo de violación o vulneración.

\section{Derecho a la verdad}

El derecho a la verdad permite facilitar los procesos de reconciliación al ayudar a comprender las causas subyacentes de los conflictos o de las violaciones generalizadas a los derechos humanos (Newman, 2009, p. 46), esto supone una obligación de investigación por parte del Estado, por cuanto cualquier situación en la que haya existido la vulneración de los derechos humanos debe ser objeto de búsqueda (Raba, 2012, p. 71). Este derecho se puede ejecutar de manera judicial como extrajudicial, la primera consiste en que el aparato jurisdiccional del Estado busque, investigue y lleve a juicio a los presuntos responsables de las graves violaciones a los derechos humanos ${ }^{14}$, y las extrajudiciales consiste en el establecimiento de comisiones de la verdad que busca obtener la información o el conocimiento de las causas que dieron origen a las violaciones con el fin de mantener una memoria histórica; con la consolidación de esta memoria se obtendrían dos consecuencias: primeramente se lograría concientizar a la sociedad para no volver a cometer los mismos errores, evitando la repetición de dichas circunstancias, y en segundo lugar se estaría evitando olvidar estas violaciones ${ }^{15}$.

Las obligaciones resultantes del derecho internacional para asegurar el derecho al acceso a la justicia y a un procedimiento justo e imparcial deberán reflejarse en el derecho interno. Por otra parte, los Estados tienen la obligación de dar a conocer información sobre todos los recursos disponibles contra las violaciones manifiestas de las normas internacionales de derechos humanos y las violaciones graves del derecho internacional humanitario; adoptar medidas para minimizar los inconvenientes a las víctimas y sus representantes; proteger su intimidad contra injerencias ilegítimas y protegerlas de actos de intimidación y represalia, así como a sus familiares y testigos, antes, durante y después del procedimiento judicial, administrativo o de otro tipo que afecte a los intereses de las víctimas; facilitar la asistencia apropiada a las víctimas que tratan de acceder a la justicia; utilizar todos los medios jurídicos, diplomáticos y consulares apropiados para que las víctimas puedan ejercer su derecho a interponer recursos por violaciones manifiestas de las normas internacionales de derechos humanos o por violaciones graves del derecho internacional humanitario. Además del acceso individual y colectivo de víctimas para que puedan presentar demandas de reparación y obtener reparación, según proceda (Leadtith, 2009, p. 4).

14 La judicial, que pretende, a través de las labores de investigación y enjuiciamiento de los responsables por violaciones de derechos humanos, reconstruir los hechos que dieron lugar a los graves crímenes cometidos (Marcellán, 2010, p. 19).

15 La no judicial, que conlleva la recopilación de información sobre las violaciones de derechos Humanos vía testimonios de supervivientes víctima y familiares de las víctimas, bases de datos de instituciones públicas y de organizaciones de la sociedad civil, análisis de expertos y académicos; el mecanismo más conocido para ello son las Comisiones de Verdad (que, en ocasiones, incluyen en su título la Reconciliación) (Marcellán, 2010, p. 20). 


\section{Derecho a la reparación}

Dentro de esta trinidad de derechos encontramos en último lugar, pero no menos importante, la reparación. La cual surge con la ocasión del daño o la vulneración de los derechos, pues cuando una persona es víctima de un injusto, merece por ese solo hecho, que las cosas vuelvan a su estado anterior, unas medidas de satisfacción por haber sufrido ese injusto y una indemnización como consecuencia de la pérdida de la cual fue víctima (Montoya, 2014, p. 7), sin embargo, no se puede estudiar este pilar desde una perspectiva simple, sino que debe ser concebido como un conjunto integral encaminado a consolidar una plena restitución (restitutio in integrum) ${ }^{16}$ (Portillo, 2015, p. 27), acompañada esta con mediadas adicionales que logren una verdadera satisfacción a la víctima ${ }^{17}$. El origen de este derecho se puede encontrar con la finalización de la segunda guerra mundial y el establecimiento de los tribunales internacionales de Tokio y Núremberg, pues siguiendo el pensamiento del profesor Portillo es desde esta fecha en que se empieza a establecer la obligación internacional de los Estados con sus asociados, los cuales deben garantizar el goce pleno de sus derechos, pero en caso de presentarse algún tipo de vulneración reparar a los afectados de estas violaciones.

Siguiendo esta nueva tendencia en el derecho internacional para 1991 se establecen los principios para la protección y la promoción de los derechos humanos mediante la lucha en contra de la impunidad ${ }^{18}$, la cual nos trae un conjunto de preceptos que constituyen la RIT, estos son: i) la reparación cubre a las víctimas, sus parientes o compañeros y, ii) estas reparaciones pueden ser practicadas de manera colectiva ${ }^{19} \mathrm{O}$ individual según lo ha presentado el profesor Noguera, quien además basándose en los principios de Van Boven/Bassiouni que se propusieron en la Asamblea General de las Naciones Unidas en el 2005, establece los siguientes instrumentos como medios que se pueden utilizar para esta reparación ${ }^{20}:$ restitución $^{21}$, indemnización ${ }^{22}$,

16 Esta consiste en "el restablecimiento de la situación anterior a la violación cometida" y en los casos en que no sea posible "el tribunal internacional puede ordenar la adopción de medidas para garantizar los derechos conculcados y reparar las consecuencias que las infracciones produjeron.

17 El numeral 18 de los principios y directrices básicos sobre el derecho de las víctimas de violaciones a las normas intencionales de los derechos humanos a interponer recursos y obtener reparaciones

18 Sesión $43^{\circ}$ de las naciones unidades en agosto de 1991

19 Estas medidas colectivas son: las de carácter simbólico a título de reparación moral tales como el reconocimiento público y solemne por parte del Estado de su responsabilidad, las declaraciones oficiales restableciendo la dignidad de las víctimas, las ceremonias conmemorativas, la denominación de vías públicas, los monumentos, todo esto en la idea de considerar el deber de la memoria (Noguera, 2010, p. 101)

20 Resolución 5683/2001 de la asamblea general de las naciones unidas

21 La restitución siempre que sea posible, ha de devolver a la víctima a la situación anterior a la violación manifiesta de las normas internacionales de derechos humanos o la violación grave del Derecho Internacional Humanitario. La restitución comprende, según corresponda, el restablecimiento de la libertad, el disfrute de los derechos humanos, la identidad, la vida familiar y la ciudadanía, el regreso a su lugar de residencia, la reintegración en su empleo y la devolución de sus bienes (Noguera, 2010, p. 102).

22 La indemnización ha de concederse, de forma apropiada y proporcional a la gravedad de la violación 
rehabilitación ${ }^{23}$, satisfacción ${ }^{24}$ y garantías de no repetición; con la aplicación de cada una de estas medidas se llevará a que la víctima tenga un pleno resarcimiento.

\section{RIT en el contexto regional}

A nivel regional en la Convención Americana sobre Derechos Humanos (en adelante CADH o pacto de San José) se estipula como principio convencional que en los casos de verificarse la violación de alguno de los derechos y libertades que esa misma convención protege, la Corte dispondrá que se garantice al lesionado en el goce de su derecho o libertad conculcados, dispondrá asimismo, si ello fuera procedente, que se reparen las consecuencias de la medida o situación que ha configurado la vulneración de esos derechos y el pago de una justa indemnización a la parte lesionada, disposición consagrada en el numeral primero del artículo 63 del pacto de San José, este parámetro convencional ha tenido en la Corte IDH un notorio desarrollo jurisprudencial, de esta manera esta corporación interamericana ha indicado que toda violación de una obligación internacional que haya producido daño comporta el deber de repararlo adecuadamente, y que esa disposición recoge una norma consuetudinaria que constituye uno de los principios fundamentales del Derecho Internacional contemporáneo sobre responsabilidad de un Estado (Corte IDH, 2014, Caso Rodríguez Vera, parr. 542), asimismo, las reparaciones ordenadas por el Tribunal deben tener un nexo causal con las violaciones declaradas en la Sentencia (Corte IDH, 2014, Caso Espinoza Gonzales, parr. 330), y con referencia al

y a las circunstancias de cada caso, por todos los perjuicios económicamente evaluables que sean consecuencia de violaciones manifiestas de las normas internacionales de derechos humanos o violaciones graves del Derecho Internacional Humanitario (Noguera, 2010, p. 103)

23 La rehabilitación ha de incluir la atención médica y psicológica, así como servicios jurídicos y sociales (Noguera, 2010, p. 103)

24 La satisfacción ha de incluir, cuando sea pertinente y procedente, la totalidad o parte de las medidas siguientes:

a) Medidas eficaces para conseguir la cesación de las violaciones continuadas;

b) La verificación de los hechos y la revelación pública y completa de la verdad, en la medida en que esa revelación no provoque más daños o amenace la seguridad y los intereses de la víctima, de sus familiares,

de los testigos o de personas que han intervenido para ayudar a la víctima o impedir que se produzcan nuevas violaciones;

c) La búsqueda de las personas desaparecidas, de las identidades de los niños secuestrados y de los cadáveres de las personas asesinadas, y la ayuda para recuperarlos, identificarlos y volver a inhumarlos según el deseo explícito o presunto de la víctima o las prácticas culturales de su familia y comunidad;

d) Una declaración oficial o decisión judicial que restablezca la dignidad, la reputación y los derechos de la víctima y de las personas estrechamente vinculadas a ella;

e) Una disculpa pública que incluya el reconocimiento de los hechos y la aceptación de responsabilidades;

f ) La aplicación de sanciones judiciales o administrativas a los responsables de las violaciones;

g) Conmemoraciones y homenajes a las víctimas;

h) La inclusión de una exposición precisa de las violaciones ocurridas en la enseñanza de las normas internacionales de derechos humanos y del Derecho Internacional Humanitario, así como en el material didáctico a todos los niveles (Noguera, 2010, p. 103). 
contenido de esta reparación, la Corte estipula que: La reparación del daño ocasionado por la infracción de una obligación internacional requiere, siempre que sea posible, la plena restitución (restitutio in integrum), que consiste en el restablecimiento de la situación anterior ${ }^{25}$. (Corte IDH, 2014, Caso Rodríguez Vera, parr 543) como se evidencia, la Corte exigió, para la plena reparación y el verdadero cumplimiento de esta obligación, la existencia de medias complementarias que con la ayuda del profesor Noguera podemos identificarlas de la siguiente manera:

Investigar los hechos, identificar, juzgar y sancionar a los responsables:

a) La obligación de investigar violaciones de derechos humanos es una de las medidas positivas que deben adoptar los Estados para garantizar los derechos reconocidos en la Convención. Así, desde su primera sentencia esta Corte ha destacado la importancia del deber estatal de investigar y sancionar las violaciones de derechos humanos, el cual adquiere particular importancia ante la gravedad de los delitos cometidos y la naturaleza de los derechos lesionados (caso Rodríguez vera vs Colombia).

b) Identificar a las víctimas de los hechos: esta medida busca establecer quien es la persona que en verdad merece o es acreedora de los derechos como víctima.

c) Mecanismos colectivos de seguimiento para verificar el cumplimiento de las órdenes de la Corte.

d) Desarrollar programas formativos en derechos humanos para funcionarios públicos: con lo cual se busca informar y dar a entender a las fuerzas armadas y públicas las obligaciones que recaen sobre ellos como agentes del Estado.

e) Difusión de la jurisprudencia del SIDH.

f) Fortalecer los controles en los centros de detención.

g) Restitución: comprende cada uno de los derechos que fueron violados y agraviados con las acciones delictivas, como la libertad, la identidad, la vida familiar, la ciudadanía y demás derechos que pudieren haber sido violados.

h) Indemnización: esta debe ser apropiada y proporcionada a los daños ocasionados por la violación.

i) Rehabilitación: para el autor deben incluir la atención médica y psicológica, así como servicio jurídico y social.

25 De no ser esto factible, como ocurre en la mayoría de los casos de violaciones a derechos humanos, el Tribunal determinará medidas para garantizar los derechos conculcados y reparar las consecuencias que las infracciones produjeron. Por tanto, la Corte ha considerado la necesidad de otorgar diversas medidas de reparación, a fin de resarcir los daños de manera integral, por lo que además de las compensaciones pecuniarias, las medidas de restitución, rehabilitación, satisfacción y garantías de no repetición tienen especial relevancia por los daños ocasionados (Corte IDH, 2014, Caso Rodríguez Vera, parr. 543). 
j) Garantías de no repetición: para la Corte y según lo manifiestan Juan Daniel López y Juana Aines Acosta, en desarrollo de estos principios la Corte IDH ha establecido tres tipos de reparación a nivel individual, una reparación material consistente en la indemnización por el daño emergente y el lucro cesante, y las otras son una reparación por patrimonio familia y proyecto de vida.

Es en este aspecto en el que el derecho procesal convencional de los derechos humanos, a través de la jurisprudencia, constituye el mayor desarrollo al grado de servir como ejemplo o fuente a otros órganos jurisdiccionales, porque si bien es cierto en la Convención ADH es donde se estipula la obligación a los Estados parte a resarcir el daño, es en cada sentencia condenatoria de la Corte IDH en la que se construye el cómo se deberá realizar la reparación integral (Martínez, 2014, p. 139).

\section{RIT en el marco interno}

\section{RIT en Colombia}

Colombia desde 1995 con el Caso Caballero Delgado y Santana del 8 de diciembre de ese año hasta el 2015 ha sido condenada 15 veces por la Corte IDH, en cada uno de esos casos se ha establecido condenas de reparación para el país, esta realidad ha traído consigo un gran reto al Estado colombiano, ante estas demandas internacionales de cumplir con su obligación de reparar, en esta tarea desde el 2004 en adelante el Concejo de Estado empezó a realizar un avance jurisprudencial significativo encaminado a realizar un diálogo jurisprudencial con la Corte IDH y cumplir con los requerimientos de la restitutio in integrum; por otro lado, en la Administración Estatal se orquestó la realización de una ley que permitiera cumplir con estos deberes, la cual se profirió en el 2011 y se instituyó como la Ley de Víctimas y Restitución de Tierras; estas son las dos formas como Colombia quiere cumplir con los objetivos de reparación integral alcanzado, por consiguiente las expectativas internacionales y regionales, que serán estudiados a profundidad en los siguientes numerales:

\section{RIT en la Jurisprudencia del Consejo de Estado}

El magistrado Jaime Orlando Santofimio, miembro de la Sección Tercera del Consejo de Estado, apoyándose en la jurisprudencia proferida por su Corporación desde el 2008 y lo manifestado por la presidenta de esa Sección resalta que en materia de responsabilidad estatal cuando resuelven demanda o conflictos de reparación directa esta alta Corte, dentro de sus fallos estipula tres principios interamericanos al momento de reparar:

a) El deber de reparar por parte del Estado.

b) La conceptualización de la imputación definida como la verificación de la realización de la conducta y según el acervo probatorio determina la responsabilidad (teniendo en cuenta la imputación objetiva). 
c) La reparación: pero no una simple reparación monetaria sino una justa reparación donde se contribuya al esclarecimiento de la verdad, la protección y demás mecanismo que reparen integralmente a la víctima.

\section{Restitución de Tierras}

Con la expedición de la Ley 1448 el Estado Colombiano creó la figura de la Restitución de Tierras como medida estatal que busca resarcir a las víctimas del conflicto armado, en primera medida el artículo noveno de la presente Ley expone todas las medidas y derechos que son adquiridos por las víctimas, y como la restitución de tierras es una de estas, más específicamente es en el artículo 25 donde encontramos la descripción de esta figura como instrumento de Reparación, al constituir que: La reparación comprende las medidas de restitución, indemnización, rehabilitación, satisfacción y garantías de no repetición, en sus dimensiones individual, colectiva, material, moral y simbólica. Cada una de estas medidas será implementada a favor de la víctima, dependiendo de la vulneración en sus derechos y las características del hecho victimizante.

La doctrina también nos ayuda en la comprensión del contenido dogmático de este mecanismo, comenzando por aclarar que su naturaleza deviene del derecho privado, pues esta medida se aplica en el momento de las violaciones a las normas, como lo divulga el observatorio de restitución y regulación de derechos de propiedad agraria, pero para la actualidad la Restitución de Tierras es:

Una opción favorable para las personas que han salido de sus territorios, a causa del conflicto armado, de la violencia en Colombia; es importante que las actividades agropecuarias, ganadería, acuicultura, caza, pesca y silvicultura acompañen el proceso de restitución de tierras, en tanto se generen las condiciones para llevar una vida digna el retornar a los espacios de los cuales fueron excluidos (Rincón, 2014, p. 10).

Dejando de ser para el caso colombiano: una acción del derecho civil para convertirse en derecho fundamental (Observatorio, 2013, p. 4), pues, con el contexto anterior se evidencia que el Estado colombiano con la expedición de la Ley 1448 tiene un clarísimo matiz reivindicatorio, y en ese sentido protector de derechos, como se puede leer a lo largo del texto (Peña, 2011, p. 21).

\section{RIT en México}

\section{Reforma Constitucional del 10 de junio del 2011}

La citada Reforma del 10 de junio de 2011 contiene modificaciones y adiciones a varios preceptos de la Carta federal que perfeccionan aspectos esenciales de la regulación de los derechos humanos internos (Fix, 2011, p. 434), de lo cual resulta importante resaltar que la promoción y protección de derechos humanos es una prioridad del Estado mexicano en su conjunto (Osorio, 2014, p. 1), de toda esta labor 
encontramos especial mención sobre la RIT pues, en la modificación del artículo primero después de reiterar la obligación del Estado de garantizar a los mexicanos sus derechos humanos se establece la carga a este para prevenir, investigar, sancionar y reparar las violaciones a los derechos humanos, en los términos que establezca la ley.

\section{Ley General de Víctimas}

Fruto de la contundente reforma constitucional del 2011, es decretada la Ley General de Víctimas considerada como un avance legislativo muy significativo en el primer título de esta normatividad, prevé los conceptos preliminares e indispensables para la aplicación de dicha ley, otorgando el significado de víctima y sus correspondientes tipos, además de enunciar los principios rectores aplicables a dicha ley, como lo son: la dignidad, la buena fe, complementariedad, debida diligencia, enfoque diferencial y especializado, igualdad y no discriminación, integralidad, indivisibilidad, interdependencia, máxima protección, mínimo vital, entre otros ${ }^{26}$; con estos fundamentos la ley continua con la enunciación de los derechos a los cuales son acreedores aquellas personas que cumplen con las características que demanda la calidad de víctima, comenzando por consagrar una salvedad en dicha disposición en la cual estos derechos son meramente declarativos y no son taxativos, pues solicita que para decretar estos derechos se tengan en cuenta los parámetros constitucionales y los dispuestos en los tratados internacionales ratificados por México, de esta manera, estipula igual, que los avances universales en la materia de los derechos al acceso a la justicia dan especial protección a los derechos de las víctimas en un proceso penal, igualmente de consagrar el derecho a la verdad.

En materia de RIT la ley tiene dos campos de acción: uno de contención y el otro de reparación propiamente dicho, la misma doctrina concluye que con la ocasión de una violación entre más rápido se colabore a las víctimas se logrará mitigar y de algún modo reducir los efectos de estas conductas, por lo cual se constituyeron los derechos a la ayuda, la atención y la asistencia, por otra parte, como medios de reparación el mismo legislador estipuló un capítulo propio para la reparación integral, donde acuerda que las medidas por utilizar, en caso de vulneración a los derechos humanos de las personas, son: restitución, rehabilitación, compensación, satisfacción y medidas de no repetición, en los siguientes títulos se desarrollan con amplitud cada una de las medidas específicamente señalas que se les deben dar a las víctimas, concluyendo con la creación de un Sistema Nacional de Víctimas que busca lograr la interdisciplinariedad entre todas la instituciones estatales para un verdadero progreso en la protección a los derechos humanos ${ }^{27}$.

26 Artículo 5 de la Ley General de Víctimas.

27 Ley General de Víctimas. 


\section{CONCLUSIONES}

El imperativo principal de todo Estado es garantizar a sus habitantes la salvaguarda de sus derechos ante toda conducta u omisión que los pudiera amedrentar, sin embargo, este deber ser se enfrenta a una realidad perturbadora en la que en muchas ocasiones no puede proteger esos derechos como quisiera el Estado, circunstancias en una región como Latinoamérica tienen mayor incidencia, pues durante todo el siglo pasado y el presente se ha vivido continuamente en violencia; ante esta imposibilidad de amparo los Estados no se pueden resignar en su labor, puesto que fruto de estas violaciones a los derechos que debía proteger, le corresponde la obligación de realizar una serie de acciones con las cuales garantice a las víctimas a las que les han sido vulnerados sus derechos dentro de los cuales encontramos la reparación integral (RIT).

El RIT implica una serie de medidas que deben ser realizadas en conjunto para poder reparar efectivamente a las víctimas de dichas violaciones, medidas como se evidenció a lo largo del presente escrito han sido enunciadas y desarrolladas ampliamente por la Corte IDH, conceptos que en las legislaciones mexicana y colombiana como se resaltaron en su momento utilizaron estos medios en algunos casos de manera idéntica como el caso de la Ley de Víctimas y Restitución de Tierras y la Ley General de Víctimas, donde se acopla literalmente lo dicho por la corporación latinoamericana, mientras que en otras circunstancias se plantan formas alternativas de reparación como se nota en la jurisprudencia del Consejo de Estado colombiano que con ello no se aparta de la jurisprudencia interamericana, pues sigue cumpliendo con los mandatos convencionales.

Todo este desarrollo en particular sobre los derechos de las víctimas especialmente en lo referente a la reparación integral, son una parte de la macro labor fundamentalista que lucha contra la desigualdad para alcanzar una verdadera autonomía, el que se libra dentro de un marco común de tres principios: derechos fundamentales, democracia y justicia constitucional (Arango, 2012, p. 12), esta lucha no la libran solitariamente cada uno de los Estadios latinoamericanos, no es solo una lucha común en América Latina sino que es un mismo anhelo común a todas estas naciones, que se materializa no solo con la CADH sino con la recepción que esta ha tenido en las diferentes reformas constitucionales internas que día tras día busca alcanzar ese derecho comunitario, es un gran reto, pues requerirá también de la armonización de los derechos propios -iura propria- de la región (comunidades intraestatales, países y bloques) que, eventualmente, habrá de generar a su vez el surgimiento de un derecho común -ius commune- (Pampillo, 2012, p. 18) en nuestra región, sin embargo, cabe acotar que fruto del Sistema Interamericano de Derecho Humanos podemos establecer que existe una serie de valores comunes, centrados en la dignidad de la persona humana y los derechos que de ella irradian (Serna, 2014, p. 216). 


\section{REFERENCIAS}

Arango, R. (2012). Fundamentos del ius cosntitutionale commune en América Latina: derechos fundamentales, democracia y justica constitucional. México: UNAM.

Calderón, J. F. (2013). La reparación integral en la jurisprudencia de la Corte Interamericana de Derechos Humanos: estándares aplicables al nuevo paradigma mexicano. México: UNAM.

Casas-Casas, A. \& Herrera-Tolosa, G. (2008). El juego político de las reparaciones: un marco analítico de las reparaciones en procesos de justicia transicional. Papel Político, 13(1), 197-223.

Cortés, F. (2007). Los derechos de las víctimas de la violencia política a la verdad, la reparación y la justicia. Reflexiones sobre cuatro casos en América Latina. Estudios Políticos (31), 61-86.

Crisis Group. (2007). Los nuevos grupos armados en Colombia informe sobre América Latina. Crisis Group.

Fix, H. (2011). Las reformas constitucionales mexicanas de junio de 2011 y sus efectos en el sistema interamericano de derechos humanos. Revista Iberoamericana de Derechos Público y Administración (11), 232-255.

Gallón, G. \& Reed, M. (2007). Principios internacionales sobre impunidad y reparaciones. Comisión Colombiana de Juristas: Bogotá.

Jaime, O. (junio, 2014). Control de convencionalidad y su efecto en la responsabilidad del Estado. En S. Díaz (Presidenta). Consejo de Estado en línea de cara al país. Consejo de Estado. Bogotá, Colombia.

Jaramillo-Marín, J. (2010). Reflexiones sobre los "usos" y "abusos" de la verdad, la justicia y la reparación en el proceso de justicia y paz colombiano (2005-2010). Papeles Políticos, 15(1), 13-46.

Lozano, A. J. (2006). El concepto de víctima en derecho internacional y su alcance en la Ley de Justicia y Paz. Pensamiento Jurídico (17), 104-115.

Marcellán, A. (2010). Sobre el conocimiento de la verdad y la construcción de la memoria histórica tras graves violaciones de derecho humanos. Revista Comunicación y Ciudadanía, (4), 18-23.

Martínez, A. (2014a). Sistema Interamericano de Protección de Derechos Humanos o Sistema Latinoamericano de Protección de Derechos Humanos. En Martínez Lazcano, A. (Dir. científico). Sistemas regionales de protección de Derechos Humanos (p. 109-181). Tuxtla Gutiérrez: Editorial Revista Primera Instancia.

Miranda, (2014). El Sistema Interamericano de Derechos Humanos. E. A. Velandia. (Ed). Derecho Procesal Constitucional (pp. 591-627). Bogotá: LEGIS.

Montoya, L. F. (2014). Reparación integral de las víctimas. Bogotá: Universidad Militar Nueva Granada.

Newman, V. (2009). Falso o verdadero (¿El derecho a la verdad es norma imperativa internacional?). Internacional Law, (14), 43-69. 
Osorio, M. A. (2014). Diagnóstico sobre la implementación de la reforma constitucional de derechos humanos. México: Dirección General de Derechos Humanos y Democracia. Boletín 61.

Pampíllo, J. P. (2012). Derecho comunitario y ius commune americano: dos asignaturas pendientes para las ciencias jurídicas de nuestro continente. FORO (18), 5- 29.

Peña, L. (2011). La restitución de tierras como plataforma de transformación del conflicto en Colombia. Bogotá: Universidad Nacional de Colombia.

Portillo, J. M. (2015). La reparación integral en el Sistema Interamericano de Derechos Humanos y su implementación en los ordenamientos jurídicos de Colombia y Ecuador. Ecuador: Universidad Andina Simón Bolívar.

Raba, L. (2012). Derecho a la verdad: uno de los principales derechos en cabeza de la víctima. Una aproximación a la regulación nacional e internacional. En A. Cruz \& W. Martínez. (Ed). Anuario justicia y razón (pp. 65-95). Bogotá: Universidad Jorge Tadeo Lozano.

Rincón, B. S. (2014). ¿Por qué ha funcionado la restitución de en otros países y en Colombia no? Bogotá: Escuela Militar Nueva Granada.

Salama, P. (2008). Informe sobre la violencia en América Latina. Revista de Economía Institucional 10(18), 81-102.

Serna, J. M. (2014). El concepto del ius commune latinoamericano en derechos humanos: elemento para una agenda de investigación. México: UNAM.

Vité, S. (2009). Tipología de los conflictos armados en el derecho internacional humanitario: conceptos jurídicos y situaciones reales. International Review of the Red Cross (873), 39-66.

Documentos jurídicos

Corte IDH. Caso Espinoza Gonzáles vs. Perú. Excepciones Preliminares. Fondo, Reparaciones y Costas. Sentencia de 20 de noviembre de 2014. Serie C No. 289, Párrafo 330.

Corte IDH. Caso Rodríguez Vera y otros (desaparecidos del Palacio de Justicia) vs. Colombia. Excepciones Preliminares, Fondo, Reparaciones y Costas. Sentencia de 14 de noviembre de 2014. Serie C No. 287, Párrafo 542.

Declaración Universal de Derechos Humanos. Firma adoptada por la Asamblea General de las Naciones Unidas mediante Resolución 217 A del 10 de diciembre de 1948.

Declaración Americana de Derechos y Deberes del Hombre de 1948 firmada en la Novena Conferencia Internacional Americana el 2 de mayo de 1948.

Convención Americana sobre los Derechos Humanos.

México. Decreto del 11 de julio del 2011.

México, Ley General de Víctimas.

República de Colombia. Constitución Política de 1991.

República de Colombia (2011) Ley 1448, Ley de Víctimas y Restitución de Tierras. 